\title{
Arc instabilities during split anode calorimetry with the TIG welding process
}

\section{Stephan Egerland ${ }^{a}{ }^{*}$ Paul Colegrove ${ }^{b}$ and Stewart Williams ${ }^{b}$}

\begin{abstract}
Split anode calorimetry investigations of tungsten inert gas (TIG) arcs were conducted using a large diameter shielding gas nozzle. Some conditions displayed arc symmetry whilst others proved distinctly asymmetric. The variation of welding current and electrode tip to workpiece distance (ETWD) was studied. Decreasing the ETWD was found to increase the current density towards the arc axis but similar to a previous study of the authors, Gaussian distributions were not observed. The gas nozzle was designed to produce laminar gas flow and sound shielding behaviour, however, anode surface oxidation was found after welding; presumably caused by shielding gas contaminated with oxygen through the welding sequence. Therefore, axial arc symmetry was influenced by random effects. The conditions and reasons for the observed phenomena are explored within this paper.
\end{abstract}

Keywords: TIG welding; energy density; shielding gas nozzle; split anode calorimetry; copper oxide layer

\footnotetext{
${ }^{\text {a }}$ FRONIUS International GmbH, 4600 Wels, Austria

${ }^{\mathrm{b}}$ Department of Welding Engineering and Laser Processing, Cranfield University, Cranfield, Bedford MK43 0AL, UK

${ }^{*}$ Corresponding author: s.a.egerland@.cranfield.ac.uk
} 


\section{Introduction}

High quality welds are achievable by employing tungsten inert gas (TIG) welding requiring minimal parameter variation [1-3]. Low current TIG arcs are particularly susceptible to arc instability issues $[1,4]$ which can be overcome by increasing the welding current [4]. For example Fig. 1(a) depicts a stable uniform TIG arc of 100 amperes (A) welding current (I) whilst Fig. 1(b) reveals arc deflection with $I=$ $50 \mathrm{~A}$, both sustained under similar conditions (electrode tip to work distance $=6.0 \mathrm{~mm}$ ) upon a flat water cooled copper anode surface. Therefore it is necessary to understand the relationship between arc plasma and parent metal to improve weld pool control and process stability $[3,2,5]$.

Apart from numerical simulation [6-15], different experimental methods have been developed to study the energy distribution of TIG arcs; e.g. spectroscopy [16-23] and arc pressure measurement [24-27]. Among the experimental approaches split anode calorimetry provides reliable results for both arc current and power distribution [28-30,7,21,22,31-33]. Instead of using melting materials, this method employs two non-melting copper anode halves separated from one another by a gap of specific width, allowing for the quantification of:

- Radial density distribution of current, mainly governing welding energy $[30,34,29,28]$

- Electrical arc power distribution by multiplying current by corresponding arc voltage [35-37]

- Calorimetric arc power or heat transferred to the workpiece as a function of the arc radius $[38,29,28,30,34]$
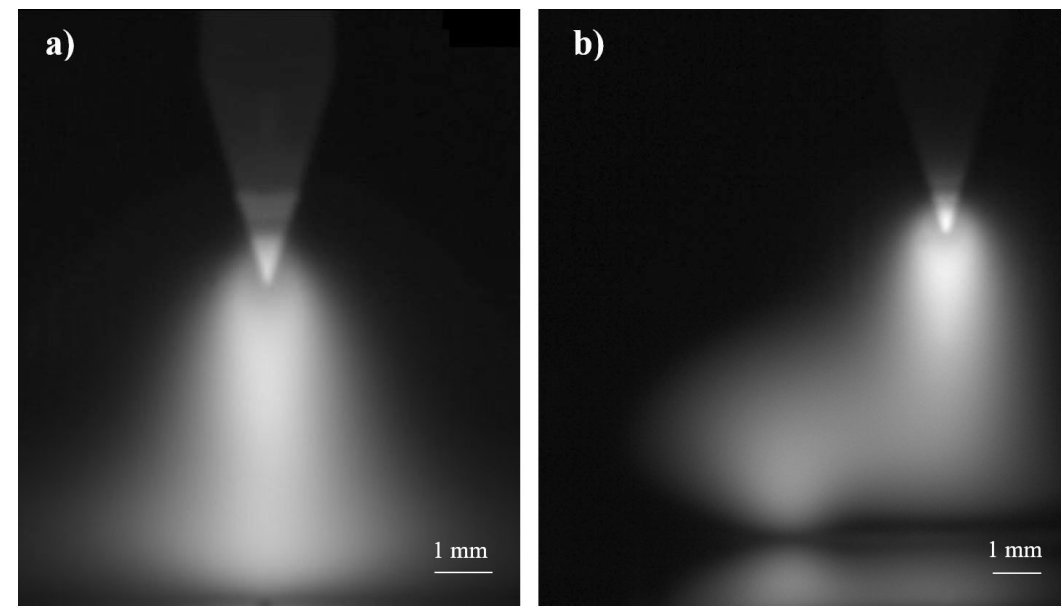

Fig. $1 a-$ symmetrically shaped TIG arc at $I=100 \mathrm{~A} ; b-\operatorname{arc}$ deflection at $I=50 \mathrm{~A}$.

Former split anode calorimetry studies made use of higher welding currents [28-30,34] and to the widest extent have stated a Gaussian-like current or power density distribution of TIG arcs [29,39,28,30,34,7]. Recent studies conducted by the authors as a preliminary trial series, focusing on an electric current envelope of 50A $\leq I \leq 100 \mathrm{~A}$ and applying a constant shielding gas nozzle diameter $(\varnothing 19.0 \mathrm{~mm})$, revealed that arc density maxima shifted away from the arc axis for lower welding currents (50A) but approached a more Gaussian-like density profile with 100 amperes [38]. 
Fig. 2 schematically represents the calorimeter principle. Plotting the current height as a function of the arc position leads to a characteristic distribution depicted in Fig. 3, which is used to calculate the arc current density as a function of the arc radius.

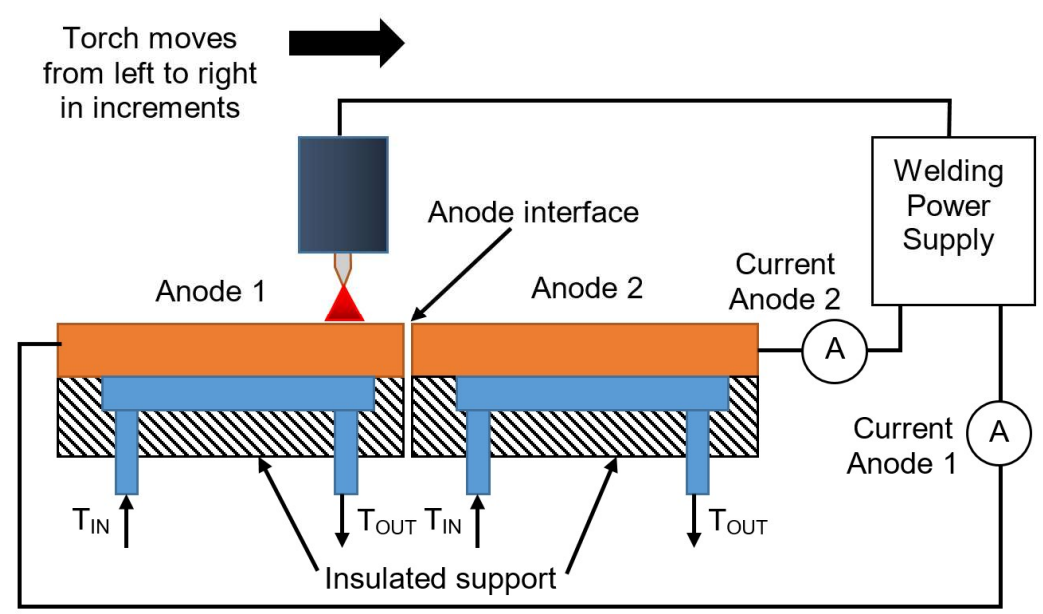

Fig. 2 Split anode calorimeter principle[38].

Whilst the current flowing into each half is measured the welding arc is traversed across the anodes in $0.2 \mathrm{~mm}$ increments, which was found in the previous study of the authors sufficient to properly resolve the distribution [38].

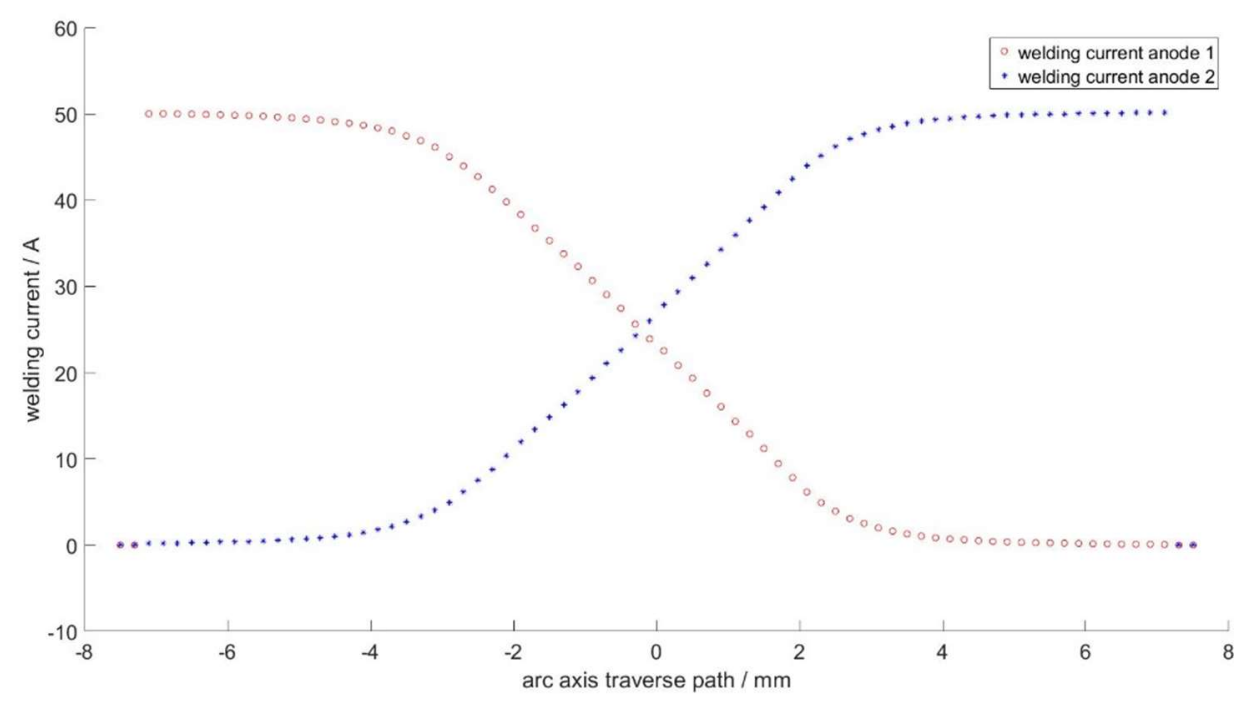

Fig. 3 Characteristic current distribution of a 50 A TIG arc as a function of the arc position. Note that zero on the $\mathrm{x}$-axis indicates the anode split plane interface.

\section{Experimental}

The calorimeter consisted of a glass fibre reinforced temperature resistant $\left(\lesssim 300^{\circ} \mathrm{C}\right)$ polyamide base with machined cooling channels. The body was mechanically joined to an interlayer of insulating synthetic resin bonded paper and rigidly fixed to the metallic gantry accommodating hardware for data acquisition and thermocouples.

Fig. 4 shows the polyamide calorimeter body including cooling channels and positions for the thermocouples electrically connected to the data acquisition system. 


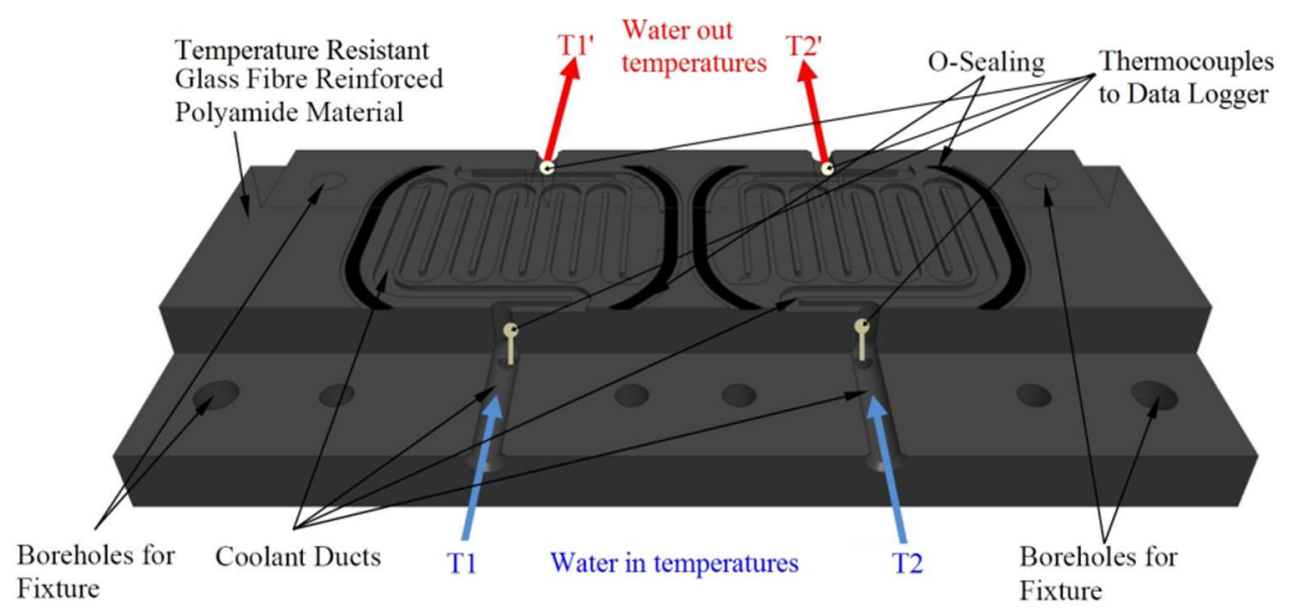

Fig. 4 Schematic calorimeter body showing cooling channels and thermocouple positions.

The calorimeter was equipped with two precisely machined ( $80 \mathrm{~mm}$ x $62 \mathrm{~mm}$ x $12 \mathrm{~mm}$ ) oxygen-free copper anodes. The anode surfaces were manually wet-ground using 500-grit abrasive paper and subsequently polished parallel to the direction of arc movement using 'Scotch-Brite ${ }^{\circledR}$ ' scouring pads. Afterwards a commercial polish (SC JOHNSON 'Stahlfix') of proprietary composition containing aluminium oxide, citric acid monohydrate, isotridecanol, and phosphoric acid was used to obtain highly polished surface quality. Before each welding sequence the parts were carefully cleaned with isopropyl alcohol. Heat-resistant and electrically non-conductive resistant polyimide film (DuPont ${ }^{\circledR}$ KAPTON ${ }^{\circledR}$ HN ' 3 mil') was added to the outer edges of each anode-half thereby providing a uniform and constant gap width of $75 \mu \mathrm{m}$ after clamping.

The welding system comprised a 'Fronius Magic Wave 2200' TIG power source equipped with cooling unit 'FK 2200' and water cooled TIG torch 'TTW 3000a F/F++/UD/4m'. The welding torch was attached to an adjustable lever arm, mounted to a gantry system equipped with a high precision linear actuator (Type: 'IAI RCA 2 SA3C') providing a repeat accuracy of $0.05 \mathrm{~mm}$. The manipulator positioned the TIG torch and the arc was ignited. A delay time of 10 seconds was applied before collecting the data which allowed the arc to stabilise upon the anode surface and to balance water inlet and outlet temperatures. Subsequently the data acquisition system was triggered to take 5 measurements maintaining a delay of 1 second between each measurement. An additional delay time of 0.5 seconds was applied after finishing the measurement before the torch moved to the next position. Data recording was conducted employing a 20 channel multiplexer data acquisition system (Type: Agilent 37490a).

The calorimeter was additionally equipped with a metal-oxide semiconductor (CMOS) camera (Type: 'IDS UI-1226LE') to observe arc stability and to correlate camera images with the output from the calorimeter. The camera was coupled and synchronised with the linear manipulator traverse path and captured two images per $0.2 \mathrm{~mm}$ increment; i.e. the camera was triggered twice to take the first image at the beginning of the increment and the second one at its end.

The electrode was $2 \% \mathrm{CeO}_{2}$ doped (WC20 type) electrode longitudinally ground using a stationary wet diamond wheel tungsten grinder (Type: 'Pro Point Plus') to precisely obtain a $36^{\circ}$ included angle. The electrode extension from the shielding gas nozzle exit was kept constant at $6.0 \mathrm{~mm}$ and argon of $99.996 \%$ purity was used as the shielding gas. A digital 'SMC PFM 725' type gas flowmeter with adjustable flow rate of $0.0083-0.42 \mathrm{Ls}^{-1}$ and display accuracy of $\pm 3 \%$ (full scale reading) was used to assure precise gas flow conditions. Fig. 5(a) shows the experimental setup, with the novel calorimeter design used in this study equipped with TIG-torch and high-resolution camera. Fig. 5(b) shows the gantry system equipped with welding torch and linear manipulator used to traverse the torch across the anodes. 

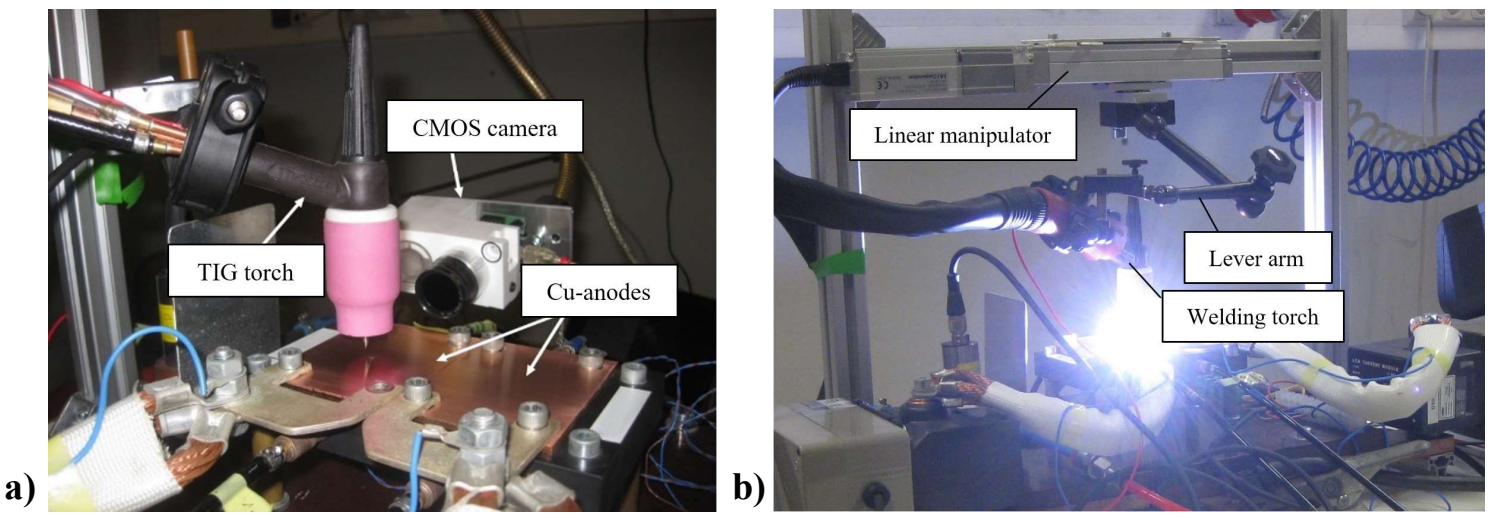

Fig. 5 a - Novel design split anode calorimeter; $b$ gantry system equipped with welding torch and linear manipulator.

The experimental gas nozzle was produced from austenitic stainless steel X8 CrNiS 18-9 according to EN 10088-2:2005 ( AISI 303) and a mesh gas diffuser was used to obtain laminar gas flow and avoid gas flow induced arc disturbance. Fig. $6(\mathrm{a} / \mathrm{b})$ depict the reference nozzle design.

a)

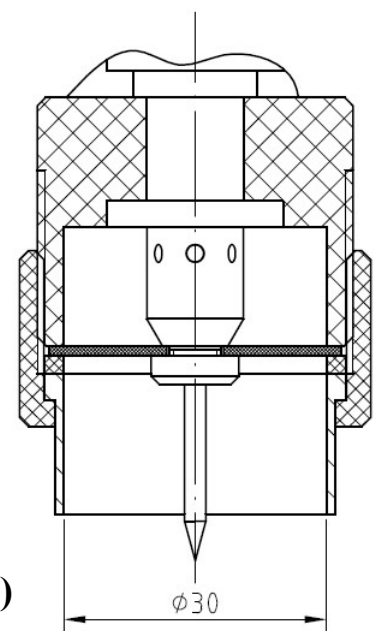

b)

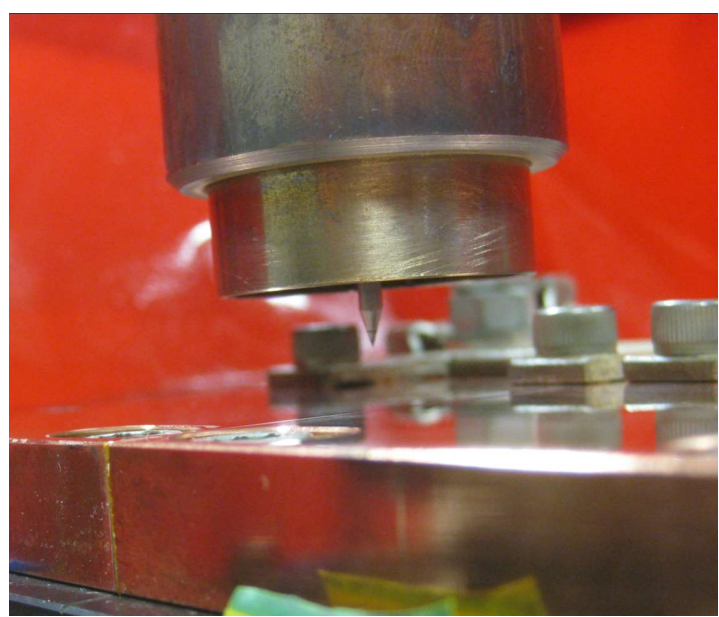

Fig. $6 a$ - Reference gas nozzle design; $b$ nozzle mounted to TIG torch.

Table 1 shows the experimental matrix developed involving a variety of parameters to correlate their interaction with gas nozzle design. This study investigated the effect of varying current and electrode tip to workpiece distance (ETWD).

\section{Table 1 Experimental matrix}

\begin{tabular}{|c|cc|}
\hline Parameter & \multicolumn{2}{c|}{ Unit/Value } \\
\hline I & $\mathrm{A}$ & $50 ; 100$ \\
ETWD & $\mathrm{mm}$ & $3.0 ; 6.0$ \\
$\alpha$ (vertex angle) & $\circ$ & 36 \\
Composition & - & $\mathrm{WCeO}_{2}$ \\
Cathode diameter & $\mathrm{mm}$ & 2.4 \\
Gas flow rate & $\mathrm{Ls}^{-1}$ & 0.3 \\
Gas flow velocity & $\mathrm{ms}^{-1}$ & 0.42 \\
\hline
\end{tabular}


Throughout this investigation three weld sequences were conducted per variable to understand the variability of the measurements.

When using split anode calorimetry the calculations assume axial arc symmetry. Plotting the measured current input, $F(x)$ to both anode halves leads to a characteristic distribution pattern, Fig. 3. The energy density decreases from the arc axis towards its boundary $(x=>\mathrm{R})$. Current and power density can be estimated as a function $f(r)$ with respect to the arc radius, Fig. 7 (b).
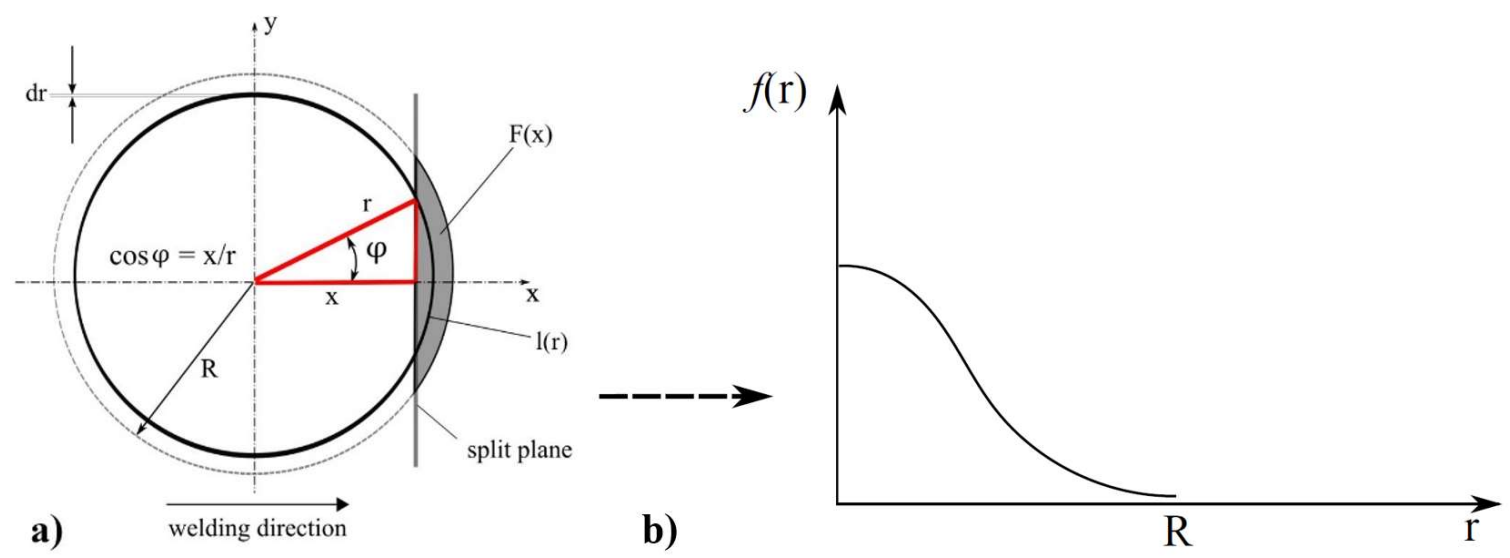

Fig. $7 a$ - Schematic split anode current distribution (note that the shaded area represents the total current or heat $F(\mathbf{x})$ supplied to anode 2$)$; $b$ radial density distribution function $f(r)$.

Fig. 7(a) draws the approach developed by Nestor [29,28] and Nestor and Olsen [39]. As indicated in Fig. 7(a) $R$, is the outer arc boundary beyond which the current density is assumed to be zero; thereby also defining the calculation regime. The radial current or power distribution is then computed for any distance $r$, from the arc axis to obtain a distribution profile similar to Fig. 7(b).

In conjunction to Fig. 7(a) we can write for the total current measured:

$$
F(x)=\int_{x}^{R} f(r) l(r) \mathrm{dr}
$$

Where $l(\mathrm{r})$, is the arc length of the circle segment at radius $r$, defined as:

$$
l(r)=r 2 \varphi
$$

Where:

$$
\varphi=\cos ^{-1}\left(\frac{x}{r}\right)
$$

We can write:

$$
F(x)=\int_{x}^{R} f(r) r 2 \cos ^{-1}\left(\frac{x}{r}\right) \mathrm{dr}
$$

Differentiation with respect to $x$, transforms (4) into an 'Abel Integration Equation' whose solution can be written as the inverse mapping of (4) [28]:

$$
f(\mathrm{r})=\frac{1}{\pi} \int_{r}^{R} F^{\prime \prime}(x) /\left(x^{2}-r^{2}\right)^{\frac{1}{2}} \mathrm{dx}
$$

Where, $F^{\prime \prime}(x)$, is the second derivative of $F(x)$ with respect to, $x$. 
Lagrange's five-point formula was used to obtain the first derivative of $F(x)$ :

$$
F_{2}{ }^{\prime}(x)=\frac{1}{12 \Delta l}\left(f_{0}-8 f_{1}+8 f_{3}-f_{4}\right)
$$

$\Delta l$ represents the increment size and, $f(i)$ the raw data at a particular position, $i$. This was applied twice to find the second derivative of $F(x)$. MATLAB $^{\circledR}$ was used to process the data and a digital polynomial smoothing filter (Savitzky-Golay filter) was used to initially smooth the raw data values. The outer arc radius, $R$, was $5.0 \mathrm{~mm}$. The welding arc was assumed centred relative to the split plane as soon as both anode halves were receiving similar amounts of electrical current conducted through the arc.

\section{Results and Discussion}

\subsection{Current density distribution}

After applying the computational approach described in Section 2, the arithmetic mean from all three trial sequences was calculated and plotted as a function of the arc radius; then, in general, these results were subjected to cubic spline smoothing to additionally smooth the curves in Fig. 8(a-d) for 'anode 1' and 'anode 2' (note both anode curves throughout were normalised to the negative x-axis). Fig. 8(a) plots the results for 50 amperes welding current and $3.0 \mathrm{~mm}$ ETWD. Fig. 8(b) reveals that doubling the ETWD to $6.0 \mathrm{~mm}$ decreases the density distribution at the arc centre vs. $3.0 \mathrm{~mm}$ ETWD and broadens the distribution of the current whilst shifting the density maximum away from the arc axis. Fig. 8(c), for $3.0 \mathrm{~mm}$ ETWD and 100 amperes welding current, shows, similar to the 50A / $3.0 \mathrm{~mm}$ ETWD sequence, that the current density rises again towards the arc centre. Finally using $6.0 \mathrm{~mm}$ ETWD and 100 amperes welding current, Fig. 8(d), flattens the current density values fairly uniform across the arc radius and, compared to $3.0 \mathrm{~mm}$ ETWD, shows lower density close to the arc axis. As an exception Fig. 8(d) interestingly shows no significant current displacement for 'anode 1' and 'anode 2' at the split plane whilst 50A welding current paired with $3.0 \mathrm{~mm}$ and $6.0 \mathrm{~mm}$ ETWD reveals considerable noise among the results. Except for Fig. 8(a), which shows considerable variation in the curves between the 'anode 1 ' and 'anode 2', the remaining graphs appear similar for both anodes.

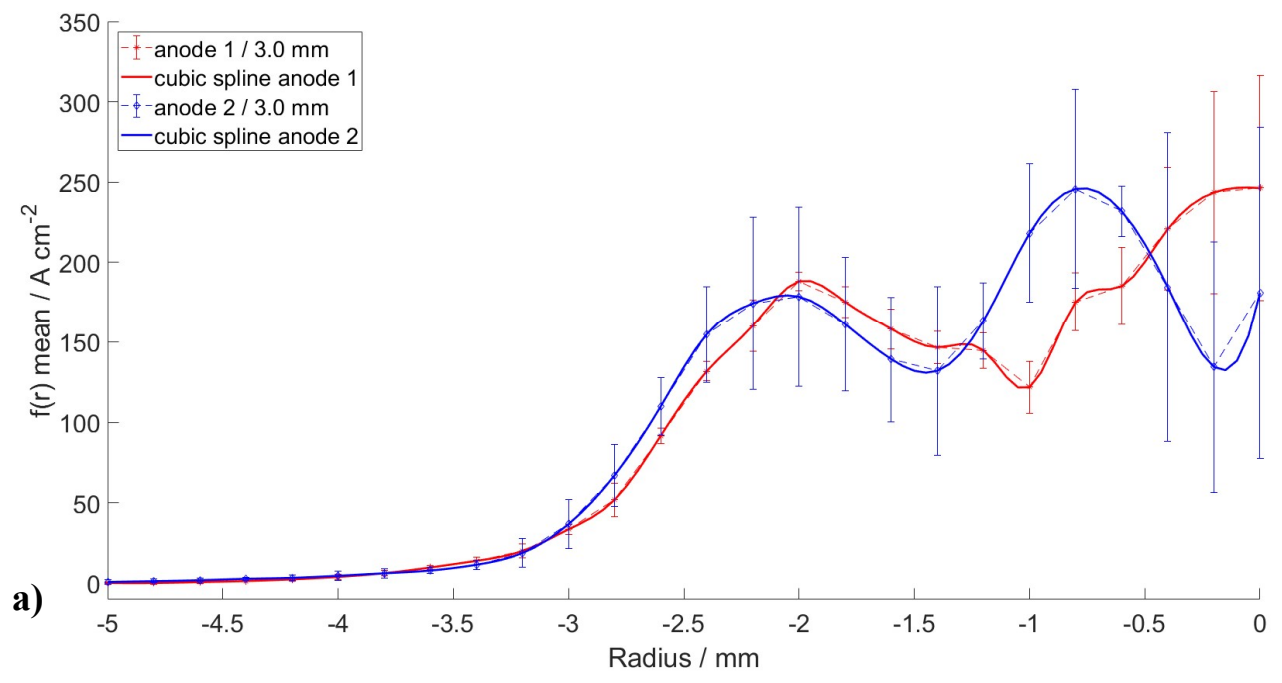



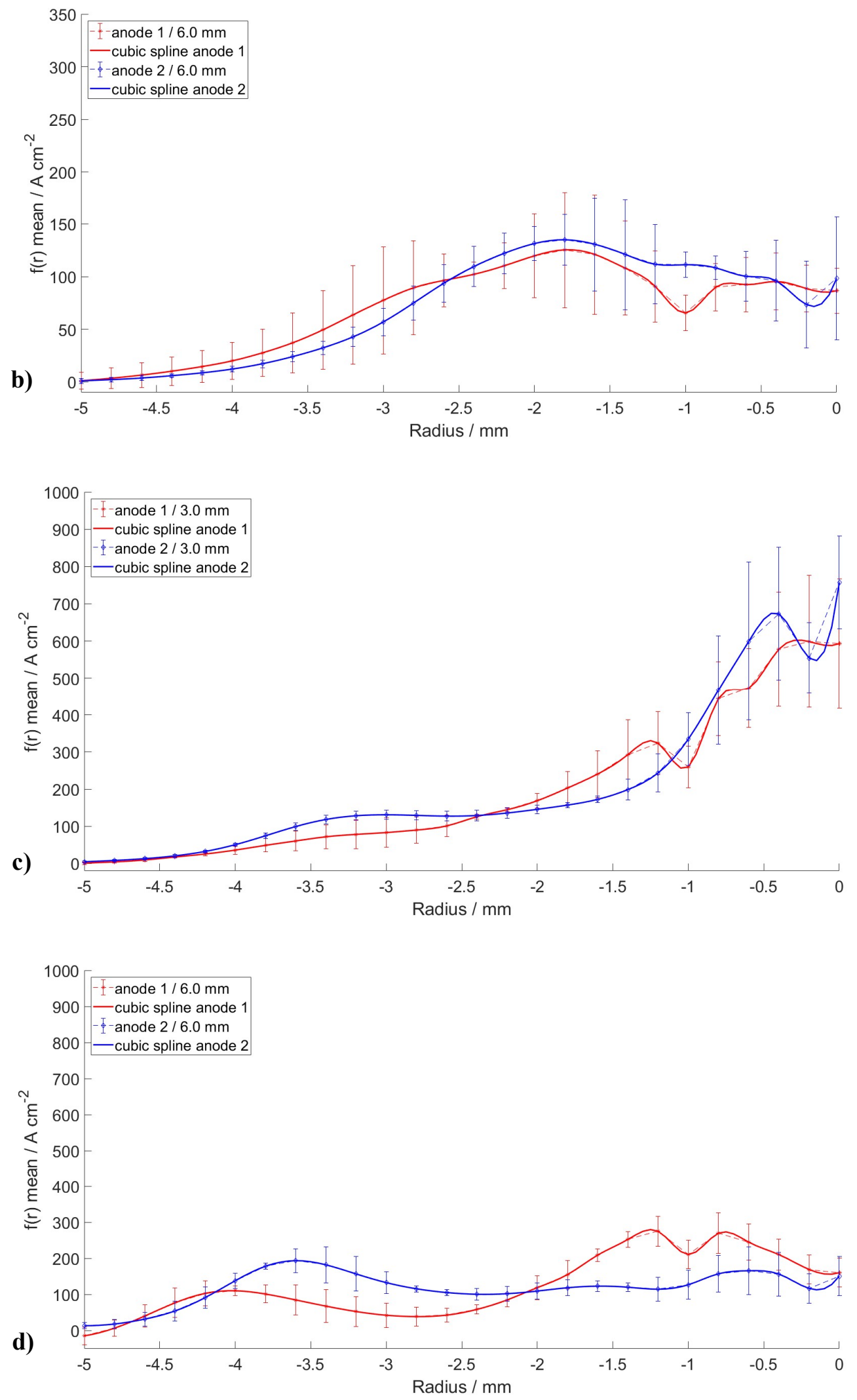

Fig. 8 a - Current density distribution as a function of arc radius and $50 \mathrm{~A}$ welding current and $3.0 \mathrm{~mm}$ ETWD; $b$ - current density distribution as a function of arc radius and 50A welding current and $6.0 \mathrm{~mm}$ ETWD; $c$ - current density distribution as a function of arc radius and 100A welding current and $3.0 \mathrm{~mm}$ ETWD; $d$-current density distribution as a function of arc radius and 100A welding current and 6.0 mm ETWD. Error bars represent the standard deviation. 
As far as the effects of "arc length" are concerned, our results are in agreement with measurements from Tanaka et al. [33], who have investigated 100A TIG arcs along with ETWD variation; as well as with results from Nestor [29] and Schoeck [36]. It is noteworthy that Nestor in his work used a welding current of $200 \mathrm{~A}$ as well as different cathode composition, cathode diameter, and, due to conducting the trials in an argon filled chamber, in general was using no gas nozzle. Schoeck has investigated argon shielded TIG arcs within a similar current envelope $(50 \mathrm{~A} ; 100 \mathrm{~A} ; 150 \mathrm{~A})$ but was using a pure tungsten cathode of bigger diameter $(\varnothing 3.2 \mathrm{~mm})$, different vertex angle $\left(45^{\circ}\right)$, and a smaller gas nozzle diameter $(\varnothing 15 \mathrm{~mm})$. All researchers found an increasing arc length radially spreads the energy density distribution and conversely to raise the current density around the arc axis when ETWD is decreased. As we could detect this phenomenon also with the lower current (50A) during our experiments we suppose it is a natural behaviour of any high intensity TIG arc $(I \gtrsim 30 \mathrm{~A})$ which would confirm results from Schoeck [36] who has suggested that the arc cross section is influenced by the "cathode jet"; i.e. a gas flow, induced by electromagnetic forces highest at the cathode and decreasing towards the anode. The arc plasma is less or even "negligibly" compressed by the Lorentz force at the anode which expands the anode spot cross section; in turn, the current density decreases.

Fig. $9(\mathrm{a} / \mathrm{b})$ shows the mean values of current density from both anodes and for all welding sequences conducted; i.e. the single curves for both anodes depicted in Fig. 8(a-d) were arithmetically averaged and plotted to the negative $\mathrm{x}$-axis.
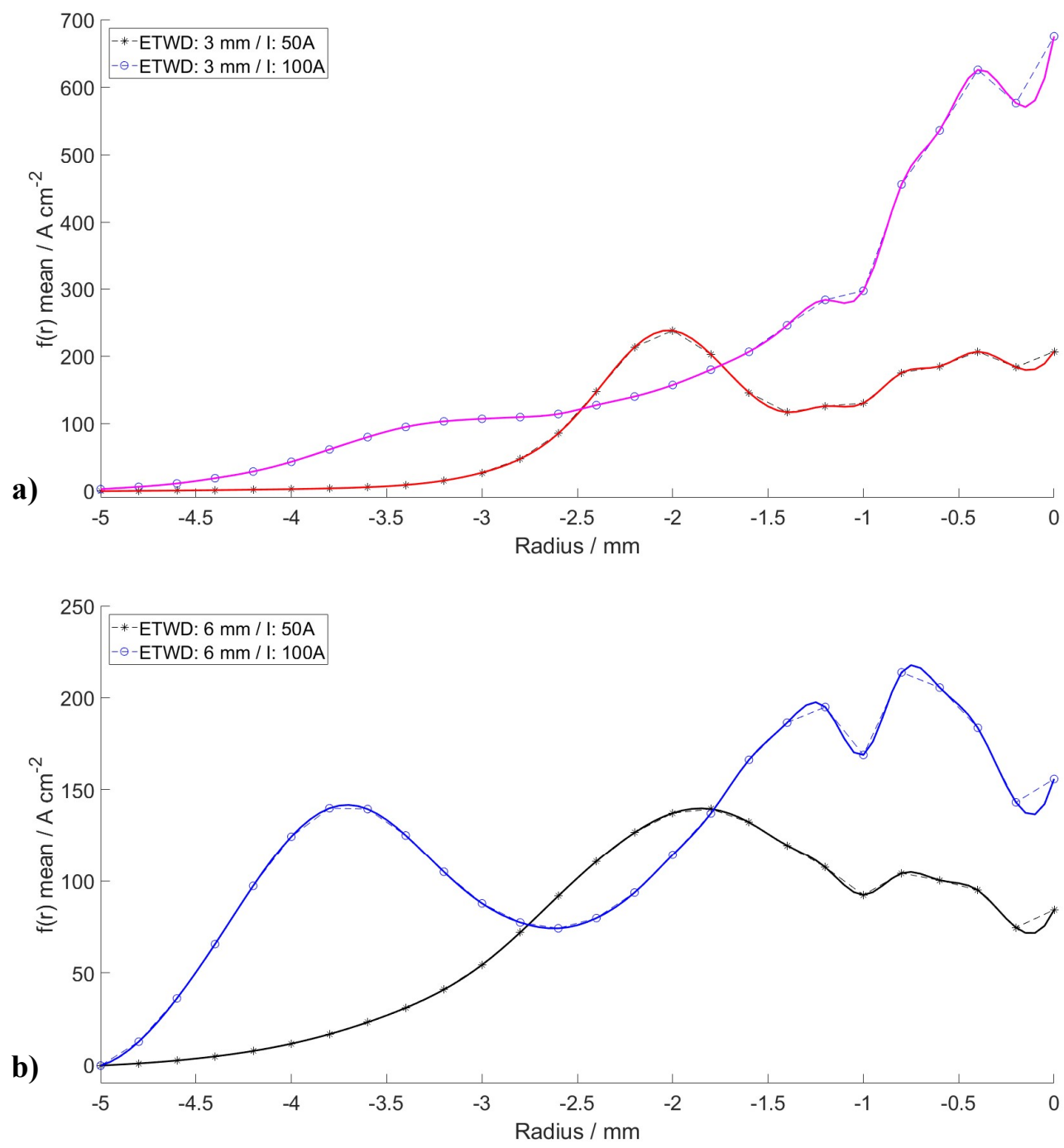

Fig. $9 a$-Curves of 'anode 1' and 'anode 2' for ETWD $=3.0 \mathrm{~mm}$ weld sequences; $b$ curves of 'anode 1' and 'anode 2' for ETWD $=6.0 \mathrm{~mm}$ weld sequences. Single curve values (Fig. 8 (a-d)) averaged and plotted to negative $x$-axis. 
Fig. 9(a/b) also shows that decreasing the ETWD whilst maintaining the welding current constant gives rise to an increase of the current density in general, which confirms findings from Schoeck and Eckert [35] and Schoeck [36]. However, differently to these researchers, who were stating Gaussian-like current density distributions, we could find a density maximum shifted away from the arc axis, which basically confirms the results from our previous study [38]. An increase of the welding current whilst keeping the ETWD constant leads to a current density increase towards the arc axis, thereby confirming results from Ushio et al. [31] and Tanaka et al. [33].

However, and we consider this as an essential finding from all welding sequences conducted, there was no 'weld current vs. ETWD' combination found in our experiments, that results in repeatable arc stability and symmetry conditions. Consequently we suppose it unlikely that higher welding currents alone, causing for example higher cathode jet velocities, may entirely assure arc symmetry under the conditions provided by our experimental setup. This supposition is worthy of further investigation to explain this phenomenon that is particularly evident in split anode calorimetry, and the 50-100 amperes current range in particular.

Except Fig. 8(d), all experiments were found to produce a distinct displacement in the current density distribution for the split interface region; i.e. the last current density values calculated for 'anode 1 ' (shortly before the arc crosses the split interface) are considerably different to the first values derived for 'anode 2'. These differences can be explained by small deflections in the arc as it crosses the split plane, which are described in the next section.

\subsection{Arc Behaviour}

Fig. 10 shows images whilst applying 50 amperes and $3.0 \mathrm{~mm}$ ETWD and correspondingly Fig. 11 shows the anode surface oxidation which is regularly shaped and does not indicate any instability at the interface. From these observations arc symmetry appears possible when using low ETWD, even when applying lower welding currents, which finally allows the proper application of the Abel Inversion.
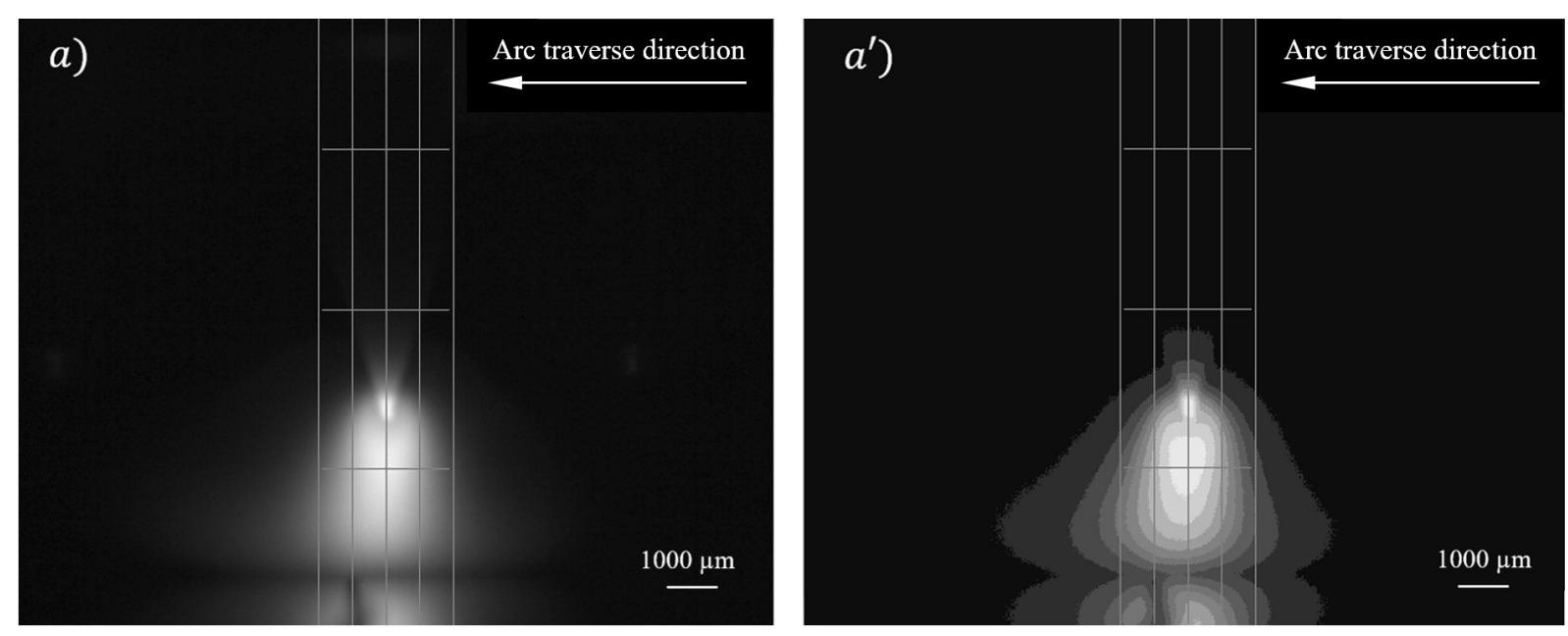

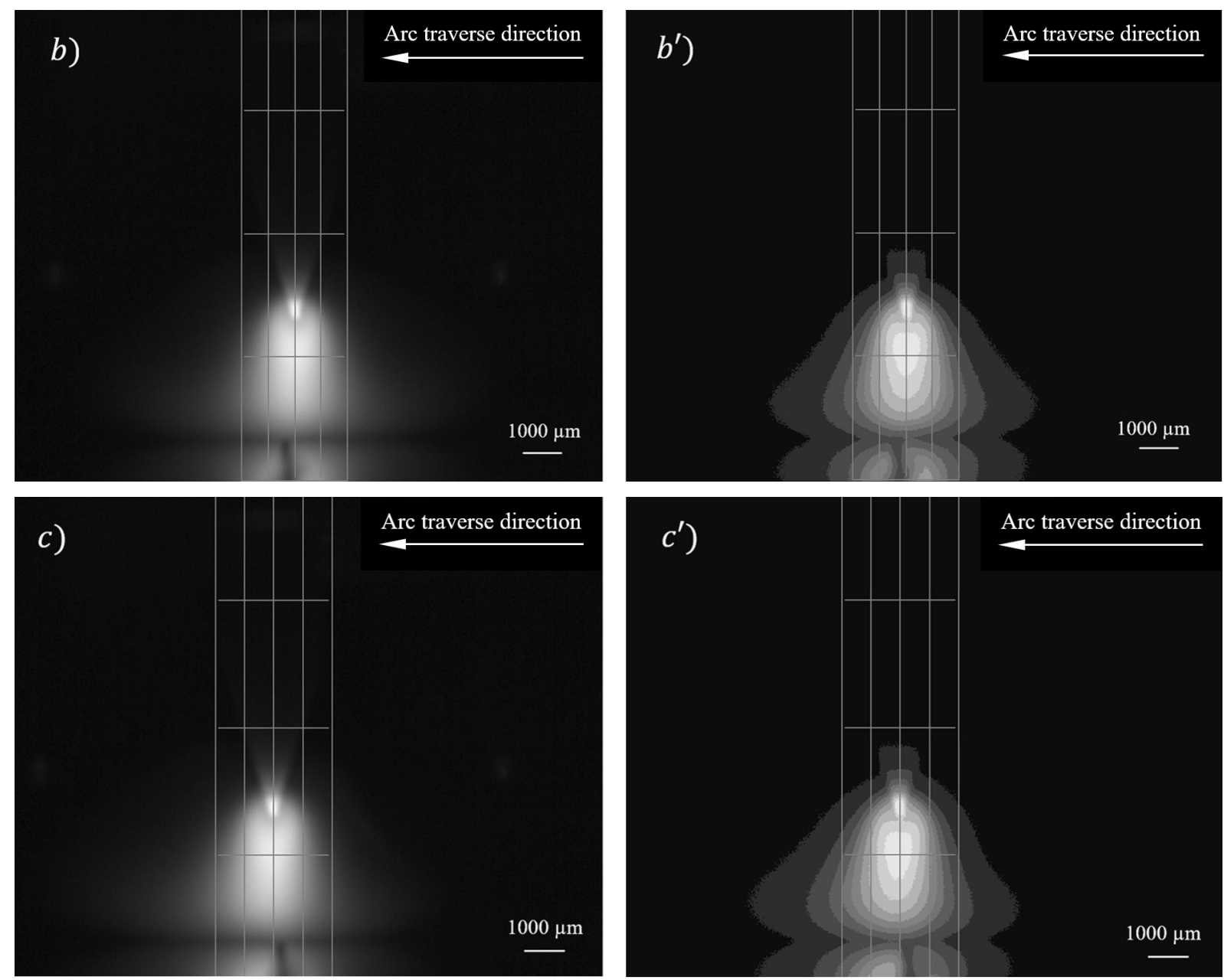

Fig. 10 High definition camera reference weld images virtually revealing axial symmetry whilst arc traversing the split plane. $I=50 \mathrm{~A}$; ETWD $=3.0 \mathrm{~mm}$. Note that from a $-\mathrm{c}$ the arc is approaching and crossing the split interface; i.e. section $a$, is $0.45 \mathrm{~mm}$ before; $b$ is close to the centre $(0.04 \mathrm{~mm})$ and $c$ shows the arc after crossing the split plane $(0.55 \mathrm{~mm})$. Sections $a^{\prime}-c^{\prime}$ depict appropriately modified image resolutions (reduced grey colour depth: 16 colours $4 \mathrm{BPP}^{\mathrm{c}}$ ).

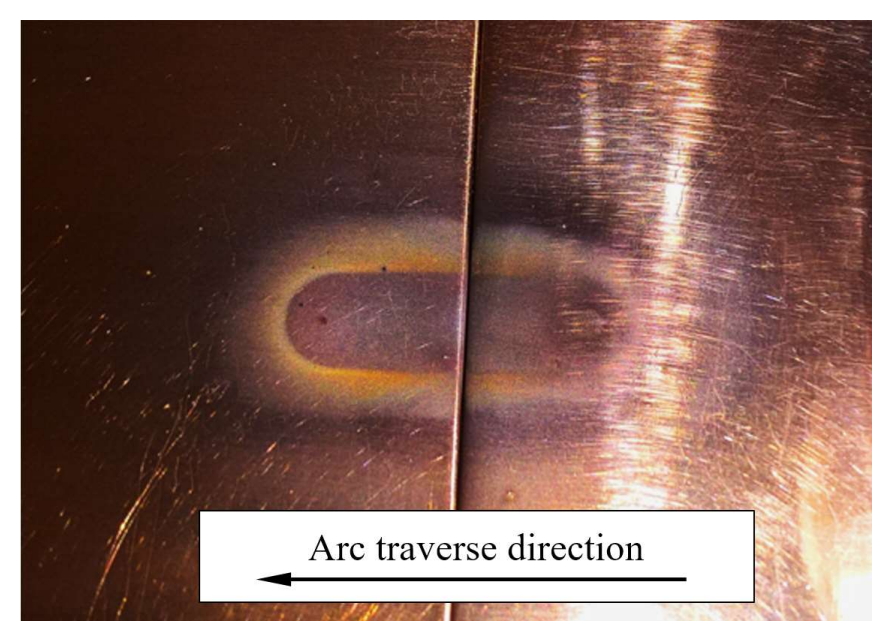

Fig. 11 Symmetric and uniform anode surface oxidation of welding sequence plotted in Fig. 10. Reference nozzle; $I=50 \mathrm{~A} ; \mathrm{ETWD}=3.0 \mathrm{~mm}$.

\footnotetext{
${ }^{\mathrm{c}}$ Bits per pixel.
} 
However, for direct comparison Fig. 12 plots an excerpt with the same parameters and clearly reveals notable deflection of the arc both prior to reaching the split interface and also remaining after crossing the split plane. This suggests that even low ETWD - in practical TIG welding applications well-known to stabilise the arc - does not necessarily assure consistent arc symmetry when applying split anode calorimetry. This supposedly leads to the noise in the calculated output as indicated by the error bars especially in Fig. 8(a).
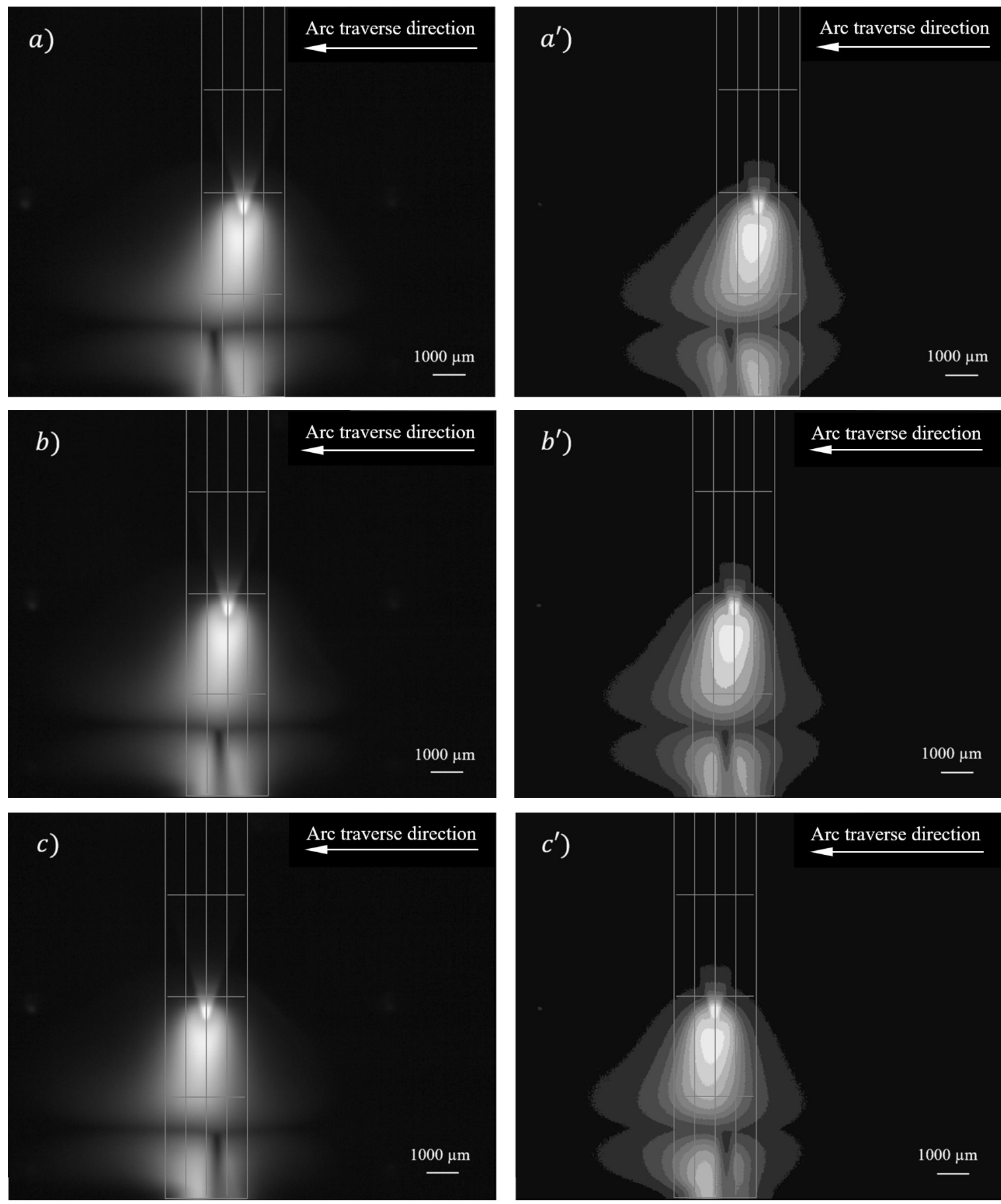

Fig. 12 High definition camera reference weld images revealing axial asymmetry whilst arc traversing the split plane. $I=50 \mathrm{~A} ; \mathrm{ETWD}=3.0 \mathrm{~mm}$. Note that from a $-\mathrm{c}$ the arc is approaching and crossing the split interface; i.e. section $a$, is $0.48 \mathrm{~mm}$ before; $b$ is close to the centre $(0.07 \mathrm{~mm})$ and $c$ shows the arc after crossing the split plane $(0.52 \mathrm{~mm})$. Sections $a^{\prime}-c^{\prime}$ depict appropriately modified image resolutions (reduced grey colour depth: 16 colours 4 BPP). Note images labelled similarly to Fig. 10. 
Fig. 13 shows for 100A and $3.0 \mathrm{~mm}$ ETWD stable arc symmetry both whilst the arc approaches and traverses the split interface. The welding voltage, compared to the $50 \mathrm{~A}$ trials, increased by $1.5 \mathrm{~V}$ in average (12.3V vs. $10.8 \mathrm{~V})$ along with doubling the weld current. An increased amount of current per unit time is transferred across the arc gap leading to both an increase in the current density around the arc centre and the power or heat transferred to the anodes. By analysing the modified photographic images in Fig. $8\left(b^{\prime}\right)$ and Fig. 13( $\left.b^{\prime}\right)$ we can find the virtual arc core region diameter (arbitrarily defined as the brightest column region in the grey colour reduced photographs) approximately doubled whilst raising the weld current from $50 \mathrm{~A}$ to $100 \mathrm{~A}$ and maintaining the ETWD constant. This also confirms results derived by Schoeck [36] who suggested that an argon shielded TIG arc must become wider to appropriately accommodate any current increase and an arc gap remaining unchanged. Schoeck in the same work particularly focuses on the importance of the cathode jet which supposedly increases with increasing weld current and, in turn, stabilises the current conducting anode spot, which might explain the reduced noise among the measurements compared to the 50A/3.0 mm ETWD weld series.

Tanaka et al. [33] postulated a Gaussian density profile for 100A weld current. However, although the current density rises more uniformly towards the arc axis with this current vs. the 50A series, this was not found in our experiments. Nonetheless the arc centre current peak values calculated from our experiments were in good agreement with the findings from Tanaka et al. [33]; despite their use of a $\varnothing$ $3.2 \mathrm{~mm}$ lanthanum-oxide $\left(2 \% \mathrm{La}_{2} \mathrm{O}_{3}\right)$ doped cathode type, different ETWD $(5.0 \mathrm{~mm})$, and different vertex angles $\left(30^{\circ} ; 45^{\circ} ; 60^{\circ}\right)$.
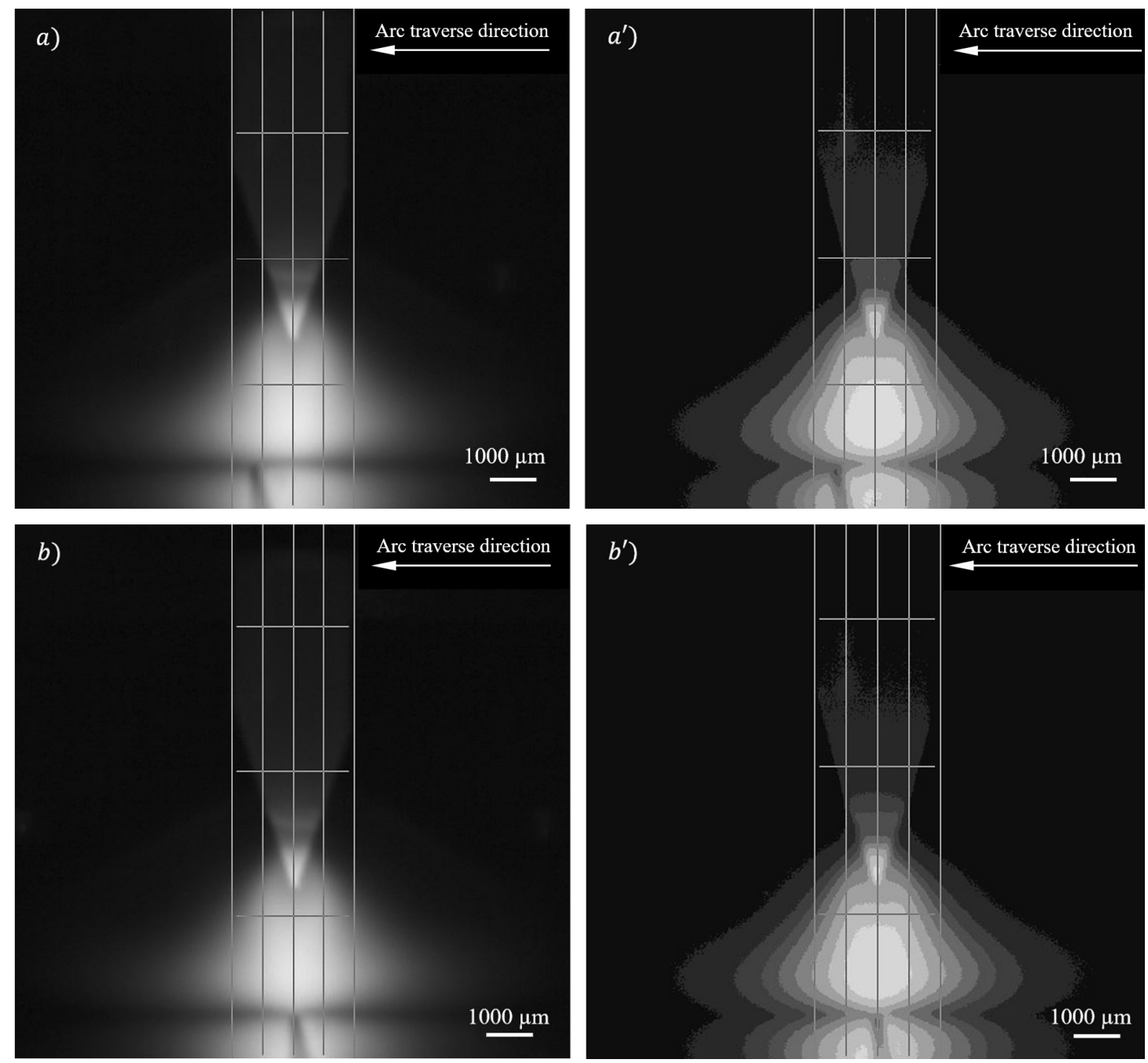

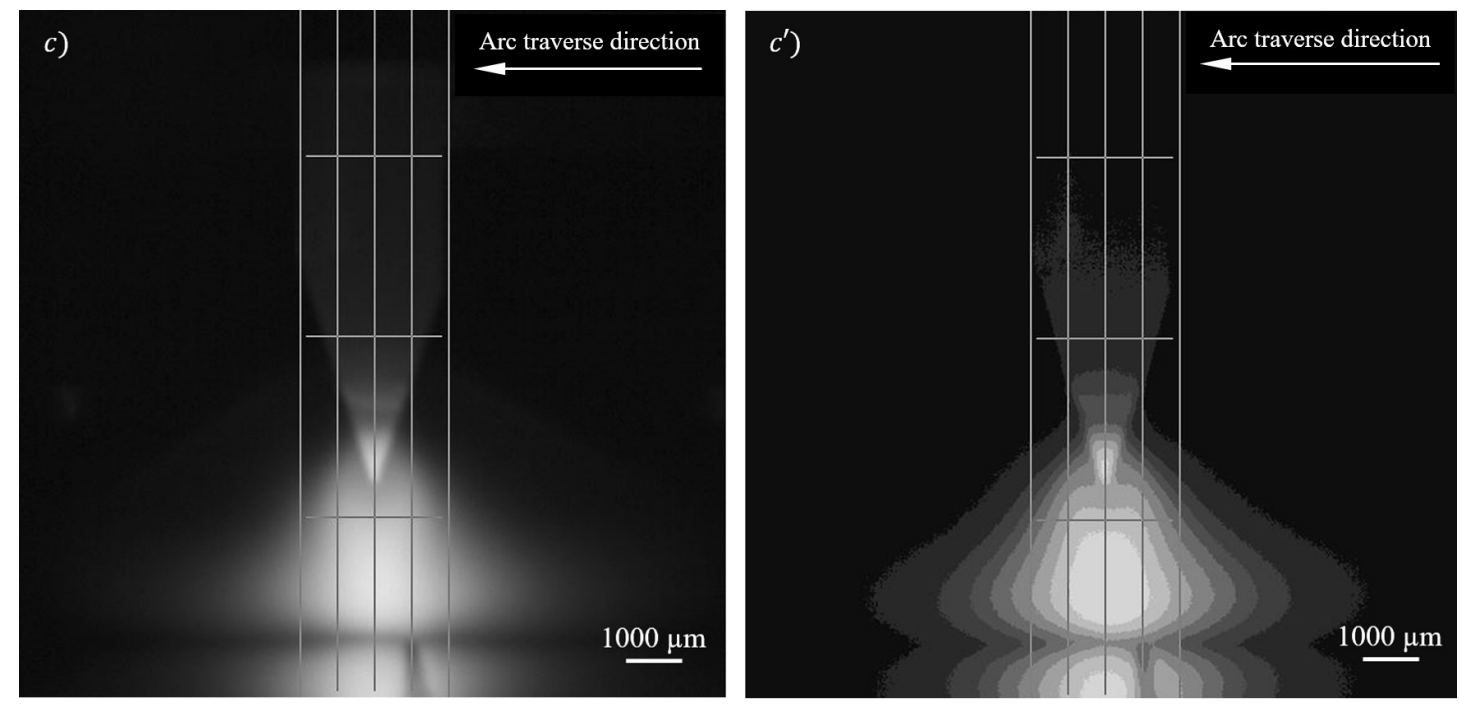

Fig. 13 High definition camera reference weld images revealing axial symmetry whilst arc traversing the split plane. $I=100 \mathrm{~A} ; E T W D=3.0 \mathrm{~mm}$. Note that from a $-\mathrm{c}$ the arc is approaching and crossing the split interface; i.e. section $a$, is $0.65 \mathrm{~mm}$ before; $b$ is close to the centre $(0.05 \mathrm{~mm})$ and $c$ shows the arc after crossing the split plane $(0.55 \mathrm{~mm})$. Sections $\boldsymbol{a}^{\prime}-c^{\prime}$ depict appropriately modified image resolutions (reduced grey colour depth: 16 colours 4 BPP). Note images labelled similarly to Fig. 10.

Fig. 14 shows high definition camera photographs of different arc positions of one of the ' $100 \mathrm{~A} / 6.0$ mm ETWD' weld sequences. Virtually no real distinction is identifiable between the real camera images $(a-c)$; however, the corresponding colour depth reduced images $\left(a^{\prime}-c^{\prime}\right)$ show that, in this particular case, the arc is distorted prior to the interface centre and obviously full axial symmetry was not achieved until the arc had passed the split plane. Comparing these images with the previous Fig. 13 sections and averaging both the arc core and the entire visible arc region one can assess similar dimensions with the arc core both for $3.0 \mathrm{~mm}$ and $6.0 \mathrm{~mm}$ ETWD, but a greater overall arc diameter for the latter. According to Schoeck [36] the current conducting region is smaller than the region that transfers heat to the anodes and although Schoeck defines the anode surface temperature independently of the current height applied uniformly with $1000^{\circ} \mathrm{C}$ the arc may become deflected due to varying temperature gradients towards the split interface (heat accumulation). Although Schoeck [36] suggests anode surface temperature effects are negligible when compared to the temperature gradient present in the arc, the temperature rise before the split plane might hence at least partially explain both the slight arc deviation prior to the split interface (see also Section 4 of this paper) but also the subsequent stabilisation after crossing the interface - providing that the heat is balanced again by thermal conduction in the second anode.
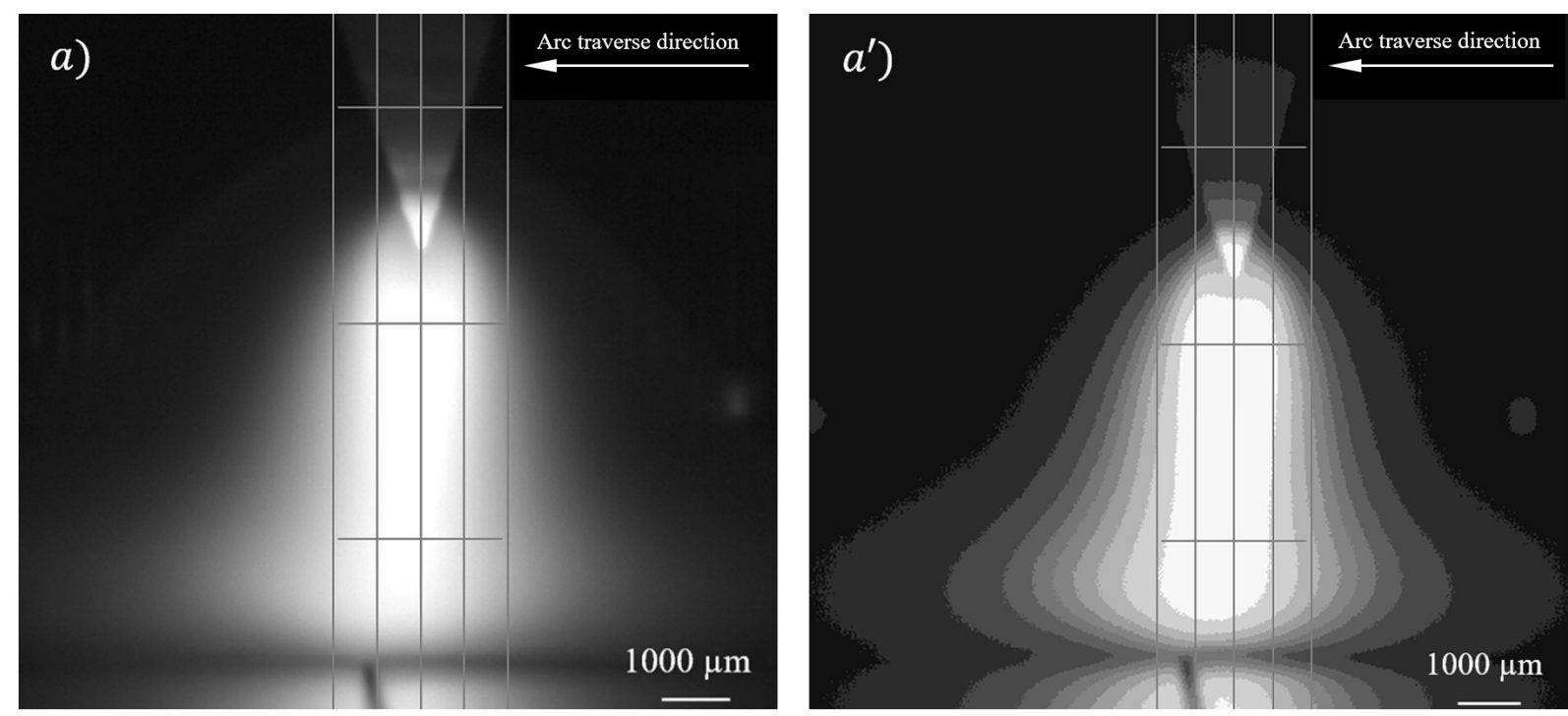

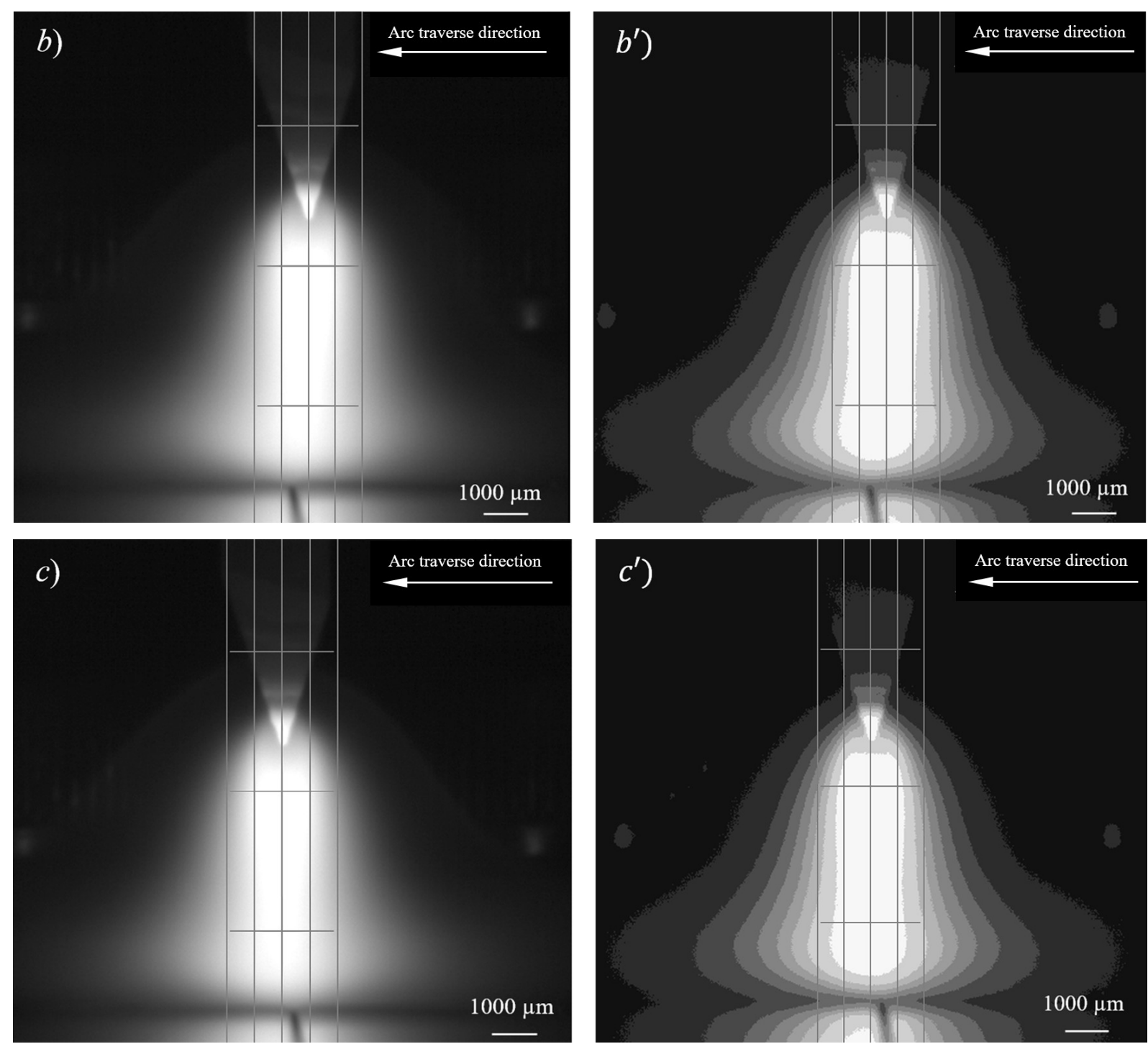

Fig. 14 High definition camera reference weld images. $I=100 \mathrm{~A}$; ETWD $=6.0 \mathrm{~mm}$. Note that from $a-c$ the arc is approaching and crossing the split interface; i.e. section $a$, is $0.47 \mathrm{~mm}$ before; $b$ is close to the centre $(0.07 \mathrm{~mm})$ and $c$ shows the arc after crossing the split plane $(0.53 \mathrm{~mm})$. Sections $a^{\prime}-c^{\prime}$ depict appropriately modified image resolutions (reduced grey colour depth: 16 colours 4 BPP). Note images labelled similarly to Fig. 10.

Finally to compare the previous results with a sequence applying $6.0 \mathrm{~mm}$ ETWD and 50A welding current, Fig. 15 virtually reveals high arc stability, hence, axial symmetry both prior to and after the arc has crossed the split interface. Plasma jet velocities have been reported to be between $\sim 180 \mathrm{~ms}^{-1}$ [9] and $\sim 130 \mathrm{~ms}^{-1}$ [36] for a 100A argon arc and increase with the current which should help to stabilise the arc. The results here however indicate that the 50A condition was more symmetric in this particular instance. Repetitive trials have indicated that the process is susceptible to random instabilities so a trial that is repeated multiple times may demonstrate symmetric behaviour during one test and nonsymmetric behaviour during the next. This may be due to the surface condition of the anodes amongst other things. Hence the symmetric behaviour in Fig. 15 and non-symmetric behaviour in Fig. 14 is not a reflection of the process conditions, but rather the random nature of this particular experiment. 

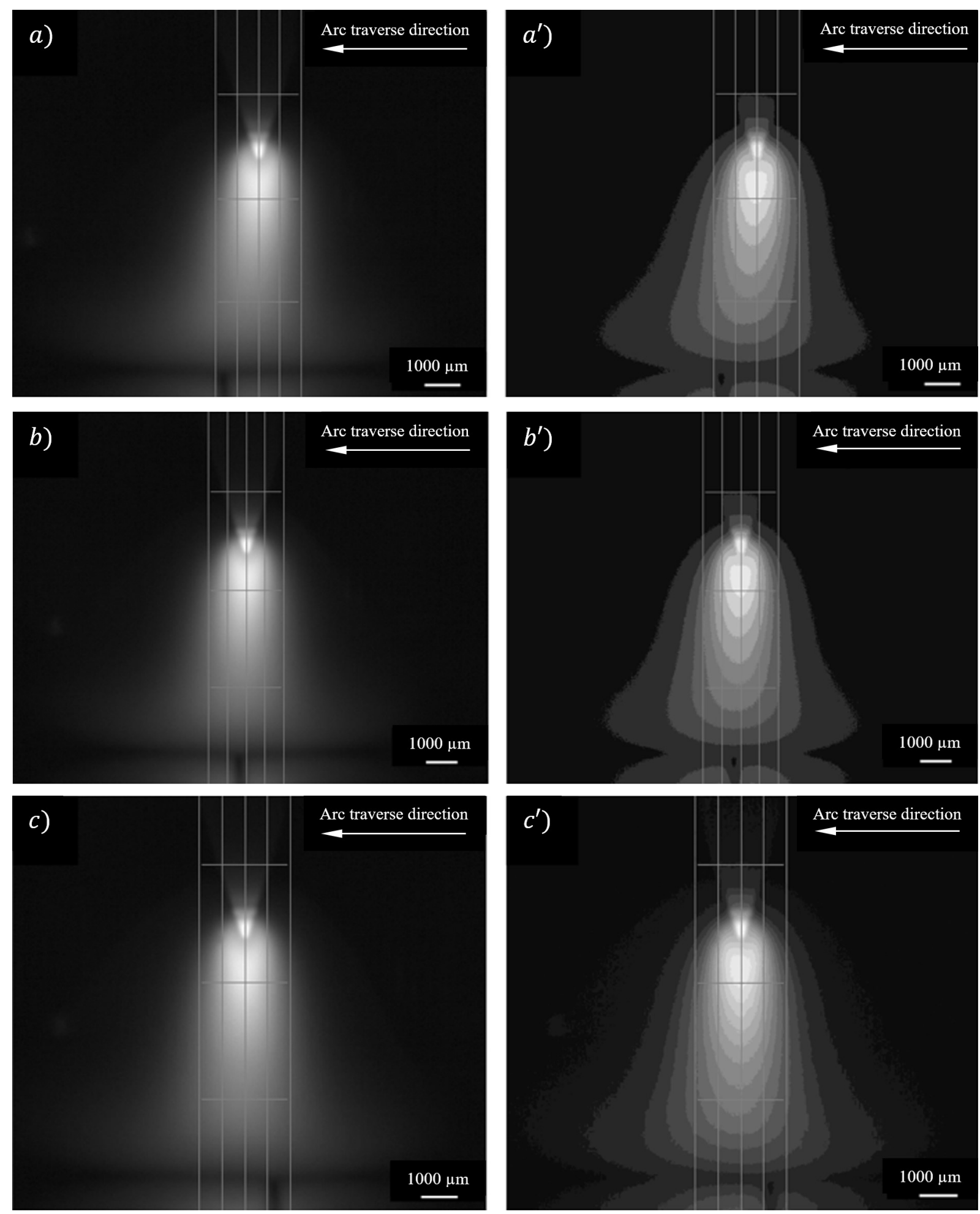

Fig. 15 High definition camera reference weld images revealing proper axial symmetry whilst arc traversing the split plane. $I=50 \mathrm{~A} ; \mathrm{ETWD}=6.0 \mathrm{~mm}$. Note that from a $-\mathrm{c}$ the arc is approaching and crossing the split interface; i.e. section $a$, is $0.90 \mathrm{~mm}$ before; $b$ is close to the centre $(0.1 \mathrm{~mm})$ and $c$ shows the arc after crossing the split plane $(0.90 \mathrm{~mm})$. Sections $a^{\prime}-c^{\prime}$ depict appropriately modified image resolutions (reduced grey colour depth: 16 colours 4 BPP). Note images labelled similarly to Fig. 10.

The next section shall be finally used to raise some considerations on the discontinuities observed. 


\section{Oxidation}

Although water-cooled anodes have been applied, various surface oxidation patterns were observed after using the reference nozzle. This is suggested in accordance to the statements from Schoeck [36] or Schoeck and Eckert [35] who assumed anode surface temperatures of $1000{ }^{\circ} \mathrm{C}$ or $927{ }^{\circ} \mathrm{C}$ respectively. According to OldBo [40] copper oxides of different chemical composition are formed at temperatures ( $t$ ) of $\sim 125^{\circ} \mathrm{C} \leq t \leq 1025{ }^{\circ} \mathrm{C}$ [40]. Cuprous oxide (copper (I) oxide or $\mathrm{Cu}_{2} \mathrm{O}$ ) is a red coloured firmly adhering oxide layer formed at temperatures of $\sim 125^{\circ} \mathrm{C}$; whilst first scaling processes take place at temperatures of $\sim 250^{\circ} \mathrm{C}$. Temperatures $\gtrsim 260^{\circ} \mathrm{C}$ lead to increased production of cupric oxide (copper (II) oxide or $\mathrm{CuO}$ ) a black coloured crystalline oxide layer. $\mathrm{Cu}_{2} \mathrm{O}$ is a semiconductor whose precise structure and thermoelectric properties are according to Korzhavyi and Johansson [41], not yet fully understood. Young and Schwartz [42] have investigated $\mathrm{Cu}_{2} \mathrm{O}$ single crystals in a temperature range of $300 \mathrm{~K}$ through $500 \mathrm{~K}$ to quantify the oxide's thermoelectric power and electrical conductivity and found the latter increasing with a rise in temperature and furthermore refer to O'Keefe and Moore [43] who have revealed that the oxide conductivity at temperatures greater than $500 \mathrm{~K}$ depends on the heat of the reaction of $\mathrm{CuO} \rightleftarrows \mathrm{Cu}_{2} \mathrm{O}$. O'Keefe and Moore [43] particularly emphasise that any interpretation of "electrical properties above $500 \mathrm{~K}$ is complicated by the fact that $\mathrm{Cu}_{2} \mathrm{O}$ is thermodynamically unstable in air at temperatures below $1000 \mathrm{~K} . "$.

We could find dark blue and even black coloured oxide layers after arc application; hence, we suppose that surface temperatures similar to those stated by Schoeck [36] and Schoeck and Eckert [35] have occurred during our experiments; i.e. the anode surface temperatures prove sufficiently high to allow for a partial reaction between oxygen and copper thereby forming different thickness oxide layers. It could however not be clarified through our experiments whether these oxides are instantaneously formed whilst the arc is interacting with the anode surface, thereby finally affecting measurement output stability; or may have formed after the arc has already passed a specific position upon the anode. For example Haessler et al. [44], although using higher welding currents in their investigation, have found that a deflected TIG arc can cause complex vortexes which lead to shielding gas contamination with air, hence oxygen.

The prototype gas nozzle was designed to derive reference data for comparison with values from experiments applying smaller diameter nozzles. The gas flow rate was chosen, according to its large diameter arbitrarily but, as derived from preliminary trials, under the consideration to maintain it constant also with those smaller nozzles. By equipping the reference part with a mesh gas diffuser, we were assuming that the nozzle is capable of producing laminar gas flow throughout the welding experiments; safely protecting anodes and arc interaction zone from contamination with oxygen. However, there are some fundamental uncertainties remaining; i.e. in dependence to weld current height and ETWD, we cannot quantify:

1. Anode surface temperature - considered to mainly affect oxidation reactions

2. Cathode jet velocity - considered to mainly affect gas flow stability

3. Degree of arc deflection - considered to induce or affect vortex phenomena

This does finally not allow us to determine the actual shielding gas flow conditions whilst applying the prototype nozzle. From the different colouration observed, however, we assume that through the welding sequence the shielding gas is contaminated with oxygen and the oxide layers found are thus the consequence of the interaction of primarily oxygen with the copper anode surface raised to higher temperatures.

Fig. 16(a/b) representatively shows for $100 \mathrm{~A}$ welding current and $6.0 \mathrm{~mm}$ ETWD significant variation in the appearance of oxides found after weld completion. In particular Fig. 16(a) shows imbalanced conditions especially around the split interface; i.e. the arc was apparently retained in the split plane vicinity which obviously led to arc deflection (note the ovality of the oxide layer at 'anode 1') and heat accumulation before the arc was crossing the split interface between both anodes. 

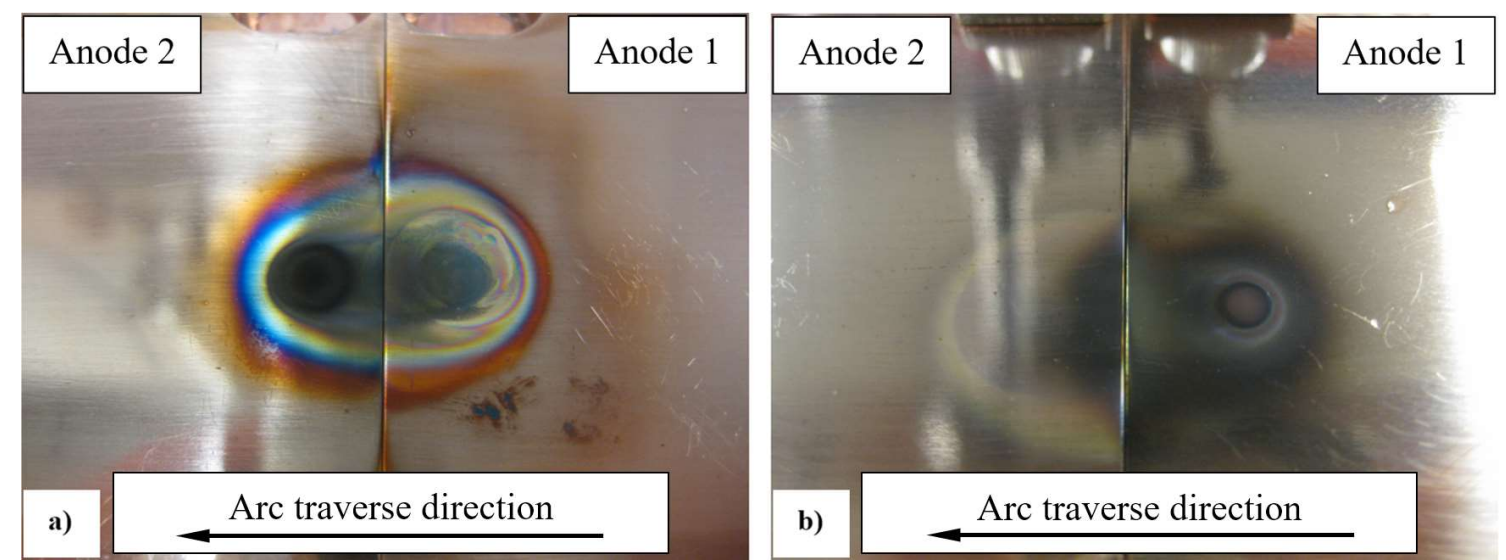

Fig. $16 a$ - Surface oxidation left by the arc after traversing the anode indicating plasma accumulation and arc asymmetry; $b$ reduced oxide traces with obviously axially symmetric anode spot, no heat accumulation, and smooth transition at the split interface. Welding conditions throughout: $I=100 \mathrm{~A}$; ETWD $=6.0 \mathrm{~mm}$.

Dependent on the actual; i.e. coincidentally affected surface condition, the anode spot may move around whilst traversing the copper-anodes, which from the camera images could - in part - occur for the $\mathrm{x}$ axis direction. Hence, although sufficient delay time was applied before triggering the data acquisition system to allow the arc to stabilise before the manipulator moves the cathode forward incrementally, the arc nonetheless appears to dynamically react with the anode surface along the traverse path. Providing that - within the boundaries of the systematic error - anode preparation quality (i.e. dimensional accuracy, surface preparation quality, etc.) was high in our experiments; arc symmetry appears thus unpredictable due to random effects - which we consider as a further essential finding from our investigation.

Notably, from Fig. 9(a/b) our results did not show Gaussian-like current density distributions; neither with $50 \mathrm{~A}$ nor with $100 \mathrm{~A}$ welding current applied. In our previous study we could find that the surface oxide layer, once over-welded, can considerably influence the current density (narrower arc and density increase towards the arc centre), and this study basically confirms the findings derived from our previous investigation [38]. The previous study, however, was conducted using anode surfaces with higher roughness grade (wet 500-grit abrasive paper and dry scouring pad grinding was applied prior to welding in [38]), as well as a smaller shielding gas nozzle diameter $(\varnothing 19.0 \mathrm{~mm})$ and lower gas flow rates $(\sim 0.17$ $\left.\mathrm{Ls}^{-1}\right)$. Also, no photographic images were taken in [38], making it difficult to directly compare both studies because of the different experimental conditions applied in both investigations.

It appears interesting, however, that the copper oxide layer once formed, seems to stabilise the arc [38] - and thus presumably arc symmetry - but obviously causes random effects whilst being generated upon the anode surface; in our understanding occurring whilst the arc stabilises along the set delay time. That brings us to suggest that the oxidation may indeed cause arc instabilities but as such is not the general root cause for the non-Gaussian current density profiles.

To the best knowledge of the authors the aforementioned phenomena; i.e. arc instability or oxidation effects and their impact on the measured data, have not been reported before in the existing literature dealing with split anode calorimetry used to analyse TIG arcs. This finally leads us to some fundamental suggestions derived from our study; i.e. either:

1. The TIG arc energy density is Gaussian distributed as long as applying means such as Nestor $[29,28]$; i.e. sealed chambers filled with argon but not using gas nozzles of any kind; or,

2. Using a gas nozzle to shield the TIG arc, which in fact would represent real industrial environment conditions, affects the measurement output, perhaps leading to non-Gaussian density profiles. However, in turn, we assume that this behaviour might have been detected also in previous investigations which were using an approach similar to ours and as such should have been taken appropriately into account by other researchers. 
Further analyses are currently being carried out of raw data obtained from welding experiments for varying gas nozzle diameter, volumetric flow rate, or gas flow velocity. It is, in turn, possible that factors are revealed stabilising arc and axial symmetry whilst traversing the arc across the split interface.

Meanwhile, this paper should primarily inspire and stimulate the discussion among the experts. However, although different in distribution, the results in this work prove basically similar to our previous study [38] which showed current and power density maxima shifted away from the arc centre. In general, Gaussian-like density distribution was also not found in this work which contradicts results from other researchers, e.g. Tsai [30], Ushio et al. [31], Tanaka et al. [33], Tsai and Eagar [34], Schoeck [36], and Schoeck and Eckert [35].

\section{Summary}

From the investigations conducted and the results achieved we can summarise the main findings as follows:

- Split anode calorimetry and a prototype gas nozzle of $30 \mathrm{~mm}$ in diameter were used to investigate TIG arc current density distribution when applying 50A and $100 \mathrm{~A}$ welding current.

- Despite high anode design accuracy and preparation quality arc deflections were found especially close to the split plane which distorted the output and are considered to underlie random effects and to significantly influence axial arc symmetry.

- Although higher arc currents and lower ETWD apparently stabilise the arc, thereby confirming results from other researchers, no experimental condition was found in our study that would reliably lead to arc stability and remain consistent throughout each trial series.

- Oxide layers were found after testing which are assumed to arise from shielding gas contamination with oxygen from the surrounding atmosphere due to turbulent flow and, as indicated by other researchers, presumably caused by arc plasma induced vortexes.

- Similar phenomena have not been reported from previous investigations which might be either based on the fact that a sealed chamber filled with argon but no gas nozzle was used, or these phenomena have not been taken into account as yet; i.e. similarly as to the approach of our study.

- It remains unclear from this investigation how far anode surface oxidation is quantitatively affecting arc symmetry; however, adverse random effects on axial symmetry are thought to occur by complex interaction between anode surface temperature and degree of anode oxidation.

- Gaussian-like current density distributions were not found in this work, hence, confirming the results from a previous study of the authors.

\section{Acknowledgements}

The authors are grateful to Mr Andreas Leonhartsberger and Mr Daniel Angermayr, both with FRONIUS International's Research and Development Department, for their unselfish assistance in respectively producing the gas nozzles and modifying the CMOS camera software. Finally, our special thanks shall be devoted to the peer reviewers for spending their valuable time to thoroughly read and comment on the paper.

\section{References}

1. Fihey J, Simoneau R Weld Penetration Variation in GTA Welding of some 304 L Stainless Steels. In: Proc. Welding Technology for Energy Applications, Gatlinburg, TN, May, 1982. pp Session D. Gas Shielded Processes, 139-153

2. Tarng YS, Tsai HL, Yeh SS (1999) Modeling, optimization and classification of weld quality in tungsten inert gas welding. Int J Mach Tool Manu 39 (9):1427-1438. doi:http://dx.doi.org/10.1016/S0890-6955(99)00013-9 
3. Juang SC, Tarng YS (2002) Process parameter selection for optimizing the weld pool geometry in the tungsten inert gas welding of stainless steel. Int $J$ Mach Tool Manu 122 (1):33-37. doi:http://dx.doi.org/10.1016/S0924-0136(02)00021-3

4. Norrish J (1st edn, 124-126, 1992) Advanced Welding Processes. IOP Publishing, Bristol

5. Tanaka M, Lowke J (2006) Predictions of weld pool profiles using plasma physics. J Phys D: Appl Phys 40 (1):R1

6. Lu M, Kou S (1988) Power and Current Distributions in Gas Tungsten Arcs. Weld, J 67 (2):29s-34s

7. Tsai M, Kou S (1990) Heat Transfer and Fluid Flow in Welding Arcs produced by Sharpened and Flat Electrodes. Int J Heat Mass Transf 33 (10):2089-2098

8. Cram L, Poladian L, Roumeliotis G (1988) Departures from equilibrium in a free-burning argon arc. J Phys D: Appl Phys 21 (3):418

9. Wu C, Ushio M, Tanaka M (1997) Analysis of the TIG Welding Arc Behavior. Comp Mater Sci 7 (3):308-314

10. Biswas K (1994) A numerical prediction of the temperature distribution in the thermionic cathode of a welding arc. J Mater Process Tech 40 (1):219-237

11. Fan H, Tsai H-L, Na S (2001) Heat transfer and fluid flow in a partially or fully penetrated weld pool in gas tungsten arc welding. Int J Heat Mass Transf 44 (2):417-428

12. Wu C, Gao J (2002) Analysis of the Heat Flux Distribution at the Anode of a TIG Welding Arc. Comp Mater Sci 24 (3):323-327

13. Ramírez MA, Trapaga G, McKelliget J (2004) A comparison between different numerical formulations for welding arc representations, J. Mater. Process. Tech. J Mater Process Tech 155:16341640

14. Lu F, Yao S, Lou S, Li Y (2004) Modeling and Finite Element Analysis on GTAW Arc and Weld Pool. Comp Mater Sci 29 (3):371-378

15. Lu F, Tang X, Yu H, Yao S (2006) Numerical Simulation on Interaction between TIG Welding Arc and Weld Pool. Comp Mater Sci 35 (4):458-465

16. Vilarinho LO, Scotti A (2004) Proposal for a modified Fowler-Milne Method to determine the Temperature Profile in TIG Welding at low Currents. J Braz Soc Mech Sci \& Eng 26 (1):34-39

17. Weglowski M (2005) Determination of GTA and GMA Welding Arc Temperatures. Weld Int 19 (3): $186-192$

18. Haddad G, Farmer A (1984) Temperature Determinations in a free-burning Arc. I. Experimental Techniques and Results in Argon. J Phys D: Appl Phys 17 (6):1189

19. Farmer A, Haddad G, Cram L (1986) Temperature determinations in a free-burning arc. III. Measurements with molten anodes. J Phys D: Appl Phys 19 (9):1723

20. Degout D, Catherinot A (1986) Spectroscopic analysis of the plasma created by a double-flux tungsten inert gas (TIG) arc plasma torch. J Phys D: Appl Phys 19 (5):811

21. Tanaka M, Ushio M (1999) Plasma State in free-burning Argon Arc and its Effect on Anode Heat Transfer. J Phys D: Appl Phys 32 (10):1153

22. Tanaka M, Ushio M (1999) Observations of the Anode Boundary Layer in free-burning Argon Arcs. J Phys D: Appl Phys 32 (8):906

23. Terasaki H, Tanaka M, Ushio M (2002) Effects of Metal Vapor on Electron Temperature in Helium Gas Tungsten Arcs. Metall Mater Trans A 33 (4):1183-1188

24. Hiraoka K, Okada A, Inagaki M (1985) Effect of Electrode Geometry on Maximum Arc Pressure in Gas Tungsten Arc Welding. Q J Jpn Weld Soc 3 (2):246-252

25. Kobayashi K, Nishimura Y, Iijima T, Ushio M, Tanaka M, Shimamura J, Ueno Y, Yamashita M (2004) Practical Application of High Efficiency Twin-Arc TIG Welding Method (SEDAR-TIG) for PCLNG Storage Tank. Weld World 48 (7-8):35-39

26. Oh DS, Kim YS, Cho SM (2005) Derivation of Current Density Distribution by Arc Pressure Measurement in GTA Welding. Sci Technol Weld Join 10 (4):442-446. doi:10.1179/174329305X44116 27. Ham HS, Oh DS, Cho SM (2012) Measurement of arc pressure and shield gas pressure effect on surface of molten pool in TIG welding. Sci Technol Weld Join 17 (7):594-600. doi: $10.1179 / 1362171812$ Y.0000000052

28. Nestor OH (1962) Heat Intensity and Current Density Distributions at the Anode of High Current, Inert Gas Arcs. J Appl Phys D 33 (5):1638-1648. doi:10.1063/1.1728803 
29. Nestor OH (1959) An Experimental Determination of Current Density and Heat Transfer Intensity Distributions at the Anode of High Current, Inert Gas Arcs. PhD Thesis, University of Buffalo, Buffalo, NY

30. Tsai N (1983) Heat Distribution and Weld Bead Geometry in Arc Welding. PhD Thesis, Massachusetts Institute of Technology, Massachusetts, USA

31. Ushio M, Tanaka M, Lowke JJ (2004) Anode Melting from free-burning Argon Arcs. IEEE T Plasma Sci 32 (1):108-117

32. Tanaka M, Lowke JJ (2007) Predictions of weld pool profiles using plasma physics. J Phys D: Appl Phys 40 (1):R1-R23. doi:10.1088/0022-3727/40/1/r01

33. Tanaka M, Terasaki H, Fujii H, Ushio M, Narita R, Kobayashi K (2006) Anode Heat Transfer in TIG Welding and its Effect on the Cross-Sectional Area of Weld Penetration. Weld Int 20 (4):268-274

34. Tsai N, Eagar T (1985) Distribution of the Heat and Current Fluxes in Gas Tungsten Arcs. Metall Tans B 16 (4):841-846

35. Schoeck P, Eckert E An Investigation of Anode Heat Transfer in High Intensity Arcs. In: Proc. Ionization Phenomena in Gases, Munich, Germany 1962. pp 1812-1829

36. Schoeck PA (1963) An Investigation of the Anode Energy Balance of High Intensity Arcs in Argon', in 'Modern Developments in Heat Transfer. Academic Press New York, New York, USA

37. Schoeck PA (1963) An investigation of the anode energy balance of high intensity arcs in argon. Modern developments in heat transfer:353-400

38. Egerland S, Colegrove P, Williams S (2016) Investigation of low current gas tungsten arc welding using split anode calorimetry. Sci Technol Weld Join:1-8. doi:10.1080/13621718.2016.1189214

39. Nestor O, Olsen H (1960) Numerical Methods for reducing Line and Surface Probe Data. SIAM review 2 (3):200-207

40. OldBo (2012) Copper - Discolouration/Scaling (in German). Haustechnik Dialog. http://www.haustechnikdialog.de/SHKwissen/1978/Anlaufen-Verzunderung. Accessed -04-17 2017

41. Korzhavyi PA, Johansson B (2011) Literature review on the properties of cuprous oxide $\mathrm{Cu}_{2} \mathrm{O}$ and the process of copper oxidation. Swedish Nuclear Fuel and Waste Management Company,

42. Young A, Schwartz C (1969) Electrical conductivity and thermoelectric power of $\mathrm{Cu}_{2} \mathrm{O}$. J Phys Chem Solids 30 (2):249-252

43. O'Keeffe M, Moore WJ (1961) Electrical conductivity of monocrystalline cuprous oxide. J Chem Phys 35 (4):1324-1328

44. M. Haessler, S. Rose, U. Fuessel, Schnick M (2012) TIG welding torch with magnetic arc oscillation and optimized shielding gas flow. Paper presented at the 65th Annual Assembly of the International Institute of Welding, Denver, USA, 
2018-03-29

\section{Arc instabilities during split anode calorimetry with the TIG welding process}

\section{Egerland, Stephan}

Springer

Stephan Egerland, Paul Colegrove and Stewart Williams. Arc instabilities during split anode calorimetry with the TIG welding process. Welding in the World, June 2018, Volume 62, Issue 4, pÿpp. 831845

https://doi.org/10.1007/s40194-018-0588-4

Downloaded from Cranfield Library Services E-Repository 